\title{
Attentional structuring, subjectivity, and the ubiquity of reflexive inner awareness
}

\section{Amit Chaturvedi}

To cite this article: Amit Chaturvedi (2022): Attentional structuring, subjectivity, and the ubiquity of reflexive inner awareness, Inquiry, DOI: 10.1080/0020174X.2022.2032324

To link to this article: https://doi.org/10.1080/0020174X.2022.2032324

曲 Published online: 03 Mar 2022.

Submit your article to this journal $₫$

Q View related articles $\sqsubset$

View Crossmark data \lceil 


\title{
Attentional structuring, subjectivity, and the ubiquity of reflexive inner awareness
}

\author{
Amit Chaturvedi \\ Department of Philosophy, University of Hong Kong, Hong Kong SAR, China
}

\begin{abstract}
Some have argued that a subject has an inner awareness of its conscious mental states by virtue of the non-introspective, reflexive awareness that any conscious state has of itself. But, what exactly is it like to have a ubiquitous and reflexive inner awareness of one's conscious states, as distinct from one's outer awareness of the apparent world? This essay derives a model of ubiquitous inner awareness (UIA) from Sebastian Watzl's recent theory of attention as the activity of structuring consciousness into an experiential center and periphery. I develop Watzl's theory into an account of UIA by suggesting that a subject is acquainted with its own conscious mental states through being reflexively aware of how these states are structured by attention into a unified subjective perspective. I favorably compare this Watzl-inspired account of UIA against other contemporary analytic and classical Buddhist accounts of reflexive awareness and subjective character, which variously ground the inner awareness of conscious states on their intrinsic phenomenal quality of 'for-me-ness', their affective/hedonic valence, or a subject's disposition to introspect them. The Watzl-inspired account also accommodates possible counter-examples to Watzl's theory posed by states of minimal phenomenal experience such as lucid dreamless sleep and nondual meditative awareness.
\end{abstract}

\section{ARTICLE HISTORY Received 29 May 2021; Accepted 24 October 2021}

KEYWORDS Reflexive awareness; attentional phenomenology; pre-reflective self-consciousness; ubiquitous inner awareness; svasamvedana

\section{Introduction}

For something that is thought by its defenders to be an essential feature of all conscious experience, the existence of reflexive self-awareness is strikingly controversial. Leaving aside the various inferential proofs which have been offered throughout the history of philosophy for the thesis that all conscious mental states are reflexively self-aware (see Janzen 2008; Ganeri 2012, ch. 10), there doesn't seem to be any definitive

CONTACT Amit Chaturvedi amitc@hku.hk Department of Philosophy, University of Hong Kong, Pokfulam Rd., Hong Kong SAR, China

(C) 2022 Informa UK Limited, trading as Taylor \& Francis Group 
phenomenological proof which would convince deniers of the thesis that they misdescribe their own experience (McClelland 2015). This impasse is all the more striking because reflexivity theorists take their view to follow from a more basic and widespread intuition about consciousness, and stake out their view from competing interpretations of this intuition by promising that reflexive self-awareness has a proprietary phenomenal character.

To give context, the more basic intuition about consciousness which motivates the reflexivity thesis is known variously as the 'Transitivity Principle' (Rosenthal 1997) or 'Awareness Principle' (Kriegel 2009):

For any mental state $M$ of a subject $S, M$ is phenomenally conscious only if $S$ is aware of being in $M$.

There are several divergent explanations of $S$ 's awareness of being in $M$. Higher-order representationalist theories generally hold that $M$ is conscious by virtue of $S^{\prime}$ 's being aware of $M$ through another higher-order and unconscious mental state which represents $M$. On the other hand, selfrepresentationalist theories believe that $S$ is aware of conscious state $M$ through M's reflexively representing itself. Still other theorists, often following the twentieth century phenomenologists, believe that $M$ is conscious not by making itself the object of self-representation; rather, $M$ intrinsically has a reflexive awareness of itself which is intransitive and non-representational. Disregarding their specific differences, though, each of these views is committed to the claim that a mental state's being conscious entails that a subject has some sort of 'inner awareness' of the mental state which is over and above the subject's 'outer awareness' of objects external to the mental state (Zahavi 2004; Kriegel 2009; Brown, Lau, and LeDoux 2019).

Reflexivity theorists of both self-representationalist and non-representationalist stripes are committed to a stronger version of the Awareness Principle, which Kriegel has called the 'Ubiquity of Inner Awareness' thesis (UIA):

For any mental state $M$ of a subject $S$, if $M$ is phenomenally conscious (at time $t$ ), then (i) $S$ is aware of being in $M$ (at $t$ ), and (ii) $S$ 's inner awareness of $M$ is part of S's overall phenomenology (at $t$ ). (Kriegel 2009, 181)

Reflexivity theorists who would accept UIA are hence committed to the view that M's reflexive awareness of itself, in virtue of which $S$ has an inner awareness of $\mathrm{M}$, makes some proprietary contribution to the total phenomenal character of S's conscious experience. While higher-order 
representationalists could claim that $S$ 's inner awareness of $M$ contributes to the phenomenal character of $M$ - either by enabling $M$ to have a phenomenal character in the first place, or by altering the representational content of $\mathrm{M}$ - the inner awareness itself is on their view unconscious, and hence does not contribute to S's phenomenology in the sense of being a distinct aspect of S's conscious experience. Reflexivity theorists, however, think not only that $S$ 's inner awareness of $M$ is responsible for $M$ 's being conscious, but that this inner awareness, being intrinsic to $M$ itself, is also a distinct if inseparable aspect of M's phenomenal character. Accordingly, some reflexivity theorists find higher-order accounts to be phenomenologically idle, in that the posit of unconscious inner awareness doesn't answer to the fact that one is experientially rather than unconsciously aware of one' own conscious states (Janzen 2008, 101). By the same token, then, the reflexivist's claim that a state is conscious only if it also conscious of itself must at some level be answerable to phenomenological facts, rather than just being the assertion of a conceptual or transcendental truth knowable only through inference.

The question then is: what exactly does M's reflexive awareness of itself contribute to the subject's overall phenomenology? Put another way, what is it like for a subject to be pre-reflectively aware of its own conscious mental state, over and above what it is like for the mental state to be conscious of an object? Reflexivity theorists will have to say that these questions are asking the same thing: A subject's pre-reflective self-consciousness of a conscious mental state is nothing but the conscious mental state's reflexive awareness of itself, since there isn't supposed to be some other mental state that is responsible for $S$ 's inner awareness of $M$, and hence for the phenomenal contribution of that inner awareness to $S$ 's experience. Once this contribution is identified, it can serve as evidence for the truth of UIA, to be cited as what has gone missing in the phenomenological reports of UIA skeptics. The demand for experiential evidence is especially pressing in the face of perhaps another equally plausible but totally contrary intuition about consciousness which has also been defended by classical and contemporary philosophers (see Mohanty 1992, 34-40; Tye 2014), namely that experience is purely 'transparent' or 'diaphanous'. The transparency of experience consists in the purported fact that the qualitative phenomenal features of conscious perceptual states are ultimately experienced as being the features of the objects experienced. That is to say, conscious states lack any proprietary phenomenal character of their own; instead, we 'see through' these states to the objects they 
are conscious of, and are never aware of the experience itself absent any subsequent introspection.

In this paper, I propose that the phenomenological impasse between UIA defenders and skeptics can be broken if we reconsider the ubiquitous role of attention in structuring conscious experience. In his 2017 book, Structuring Mind, Sebastian Watzl develops an account of attention as an activity which structures consciousness into an experiential center and periphery. His account makes a number of claims which are relevant to the debate over UIA:

(1) The attentional structure of experience has a proprietary phenomenal character which cannot be reduced to how the world appears.

(2) Through actively controlling the distribution of attention to its mental states, a subject becomes simultaneously aware of the subjective experiential structure in which those states are located.

Although the next claim is not explicitly endorsed by Watzl in his book, he does hypothetically entertain it in a couple footnotes $(2017,226 n 6 \&$ 280n42):

(3) The passively guided, non-agentive activity of attention may also make a subject simultaneously aware of how its experience is being structured, over and above its awareness of how the world appears.

Watzl further argues that:

(4) The activity of attentional structuring in either its passively or actively guided forms is a necessary feature of all conscious experience.

If (3) and (4) are true, then it would follow from (1)-(4) that:

(5) Through the awareness of its own attentional activity, a conscious subject has a ubiquitous and reflexive inner awareness of its experience as such.

It is a further upshot of Watzl's account that the activity of attention explains the essentially subjective character of consciousness, i.e. the unique and intimate experiential acquaintance that a subject has with its own conscious point of view, and that in turn serves as the privileged epistemic basis for introspective knowledge about its own experience. 
While Watzl only goes so far as to argue that a subject is acquainted with its own conscious perspective through actively shaping its attentional structure, I suggest that his account be extended in light of (3) to claim that passive attention also acquaints a subject with its own conscious perspective. In other words, whereas active attention makes one aware of being the subject of experience through being the agent of attentional structuring, passive attention would make also being the subject of experience qua being passively subject to the activity of attentional structuring and the changes it brings about in one's conscious perspective. In short:

(6) The phenomenal sense of being a subject of experience is grounded upon one's ubiquitous awareness of how attention (actively or passively) structures experience.

Together, claims (1)-(6) constitute what I call the 'Watzl-inspired' account of UIA. I think this account offers perhaps the most substantive and least question-begging version of the reflexivity thesis that has been offered by both classical and contemporary philosophers. It also stands to bolster the already significant contribution that Watzl's theory of attention makes to our understanding of phenomenal consciousness and subjectivity.

Section 2 of this paper considers attempts by contemporary reflexivity theorists such as Uriah Kriegel and Dan Zahavi to articulate the proprietary contribution of ubiquitous inner awareness to a subject's overall phenomenology in terms of what they call the subjective quality of 'for-meness'. I argue that the posit of for-me-ness is insufficient on its own for overturning a general version of the transparency intuition. Briefly, if the quality of for-me-ness just refers to the manner in which conscious mental states are presented to a subject, then there is nothing in principle that phenomenologically distinguishes this quality from the manner in which the apparent world is consciously presented to a subject.

Section 3 considers a more informative account of subjective character inspired by the Indian Buddhist philosophers Dignāga (5th cent.) and Dharmakīrti (7th cent.). Like contemporary reflexivists, Dignāga and Dharmakirti claim that each conscious state of awareness is intrinsically aware of itself in addition to being aware of some intentional object. But, they specifically identify what it is like to experience the uniquely subjective phenomenal aspect of any conscious state with that state's affective or hedonic valence. Interpreting the 'for-me-ness' or subjective character 
of experience in terms of affective/hedonic valence has the added explanatory benefit of accounting for the subject-implicating nature of experience. That is, conscious states are often not just passively presented 'for me'; rather, they often are felt as telling me to do something. The plausibly imperatival nature of affective/hedonic valence would hence grant conscious states with a phenomenally felt motivational force that shouldn't be reduced to how the world appears. Ultimately, though, I reject the Dignāga-inspired account for not being properly ubiquitous, in that there can possibly be conscious states without any felt motivational force. Also, it isn't obvious that the phenomenal character of affective/hedonic states cannot at all be assimilated to how the world appears; indeed, some representational theories of pain would claim that the motivational force of pain derives from how the body appears.

Section 4 and its subsections develop a Watzl-inspired account of UIA. Section 4.1 introduces Watzl's model of attention and the notion of phenomenal centrality structures. Through partitioning conscious states into a phenomenal center and periphery, the activity of attention generates an experiential structure whose phenomenal character cannot be reduced to the phenomenal character of the apparent world. Section 4.2 builds on Watzl's account by arguing that the inner awareness of a centrality structure and its unique phenomenal character takes place through the ubiquitous and reflexive awareness of attentional structuring in both its actively and passively guided modes. Section 4.3 examines how Watzl links the awareness of attentional activity to an explanation of phenomenal subjectivity, or the immediate acquaintance that a subject has with its own conscious point of view. I argue that Watzl's account can only explain subjectivity as an essential feature of all conscious experience if it accommodates the existence of passive attention awareness. Section 4.4 takes stock of the advantages that the Watzl-inspired account of UIA has in comparison to other reflexivity theories, as well as recent attempts by Tom McClelland (2015) and Robert Howell (2019) to ground UIA on a subject's disposition to introspectively reflect on its experience. These introspection-based accounts are found to be deficient because they cannot accommodate the existence of UIA for conscious creatures who undergo attentional activity but lack the cognitive capacities for introspective access.

Lastly, section 5 considers two potential counter-examples to Watzl's core claim that attentional structuring and attention-based subjectivity are essential to consciousness. Lucid dreamless sleep and non-dual meditative awareness are offered by Thomas Metzinger (2020) as two cases of 
minimal phenomenal experience, in which there is wakeful consciousness without any experience of intentional contents or a sense of self. With evidently nothing to attend to and no one who does the attending, minimal phenomenal experience would seem to lack the sort of phenomenal centrality structure that Watzl thinks is essential to consciousness and responsible for its unified, perspectival, and subjective character. In response, I argue that under the Watzl-inspired account, minimal phenomenal experiences would indeed have a minimal attentional structure which should preserve their attention-based subjectivity.

The conclusion of this paper is that the Watzl-inspired account of active and passive attention awareness stands as perhaps the most promising attempt by a classical or contemporary reflexivity theory to establish the existence of ubiquitous inner awareness, and articulate a form of pre-reflective self-consciousness which grounds a basic and yet nontrivial sense in which there is something it is like for conscious experience to have a subjective character. Of course, Watzl's overall theory of attention is controversial and, for all its explanatory virtues, I don't argue outright for its truth here. Actually, I don't take Watzl's theory to be fully true as stated, since I see a gap to be filled by the notion of passive attention awareness. For that matter, the phenomenological claims of the Watzlinspired account are also contentious, and cannot offer absolute proof of the account's truth. Nor do I give further independent reasons for accepting the truth of UIA. My basic conclusion - namely, that the Watzl-inspired account of reflexive inner awareness and attention-based subjectivity thusfar gives the most informative and plausible phenomenological model of ubiquitous inner awareness - simply lends tentative support to the following conditionals: If UIA is true, then the Watzlinspired account is (likely) true; and, if the Watzl-inspired account is not true, then UIA is (likely) not true.

\section{The failure of for-me-ness to secure UIA against the appearance view}

Reflexivity theorists committed to UIA need to identify the distinct contribution that reflexive inner awareness makes to a conscious mental state's phenomenal character, if they are going to change the minds of UIA skeptics who believe that experience is obviously transparent, i.e. that any conscious state is aware of some object and not of itself. To sidestep any disputes about the ontological status of the objects we experience, Watzl helpfully articulates a more general version of the transparency 
claim called the 'Appearance View'. One may think that the phenomenal properties of experience are actually properties belonging to an external object, a mental representation about an external object, or even nonintentional features of the experience itself - all the same, these disparate positions can share the view that the 'phenomenology of experience is exhausted by the way the world or an aspect of the world appears to the subject' (Watzl 2017, 162). ${ }^{1}$ That is to say, conscious mental states differ in their phenomenal character just to the extent that the mental states differ in how they present the world. The Appearance View is technically neutral on the question of whether or not those presented appearances have intentional content or are attributable to changes in the world itself. But, the view is committed to understanding the phenomenal character of experience as supervening on its appearance properties, i.e. the properties that determine what it is like for aspects of the world to appear to a subject $(2017,160-162)$.

The Appearance View draws into sharper focus the question of what it is like to be pre-reflectively and reflexively self-aware, because if there is going to be something it is uniquely like for a conscious state to reflexively experience itself, then what that is like should presumably be different from what it is like for a conscious state to simply experience an apparent world. Absent any phenomenal difference, the distinction between experiencing an object and reflexively experiencing the experience of that object would seem to collapse. Accordingly, reflexivity theorists have claimed that, apart from qualitative properties - i.e. the properties that determine what it is like to, say, taste honey or smell a rose - a conscious phenomenal state also has a subjective character which determines what it is like to experience such qualitative properties from a first-personal perspective. This subjective character is often glossed as a phenomenal aspect of 'for-me-ness' that determines all qualitative properties to be experienced as being given to or for a subject (Zahavi and Kriegel 2016) - hence, honey-taste and rose-smell are always consciously experienced as honey-taste-for-me or rose-smell-forme. This doesn't mean that the subject qua metaphysical owner of experience must always appear as part of any phenomenal state. Nor do experiences appear as being 'for me' only upon introspective reflection. Instead, 'for-me-ness' just refers to the minimal, pre-reflective sense in which every conscious experience is phenomenally present to a subjective perspective

\footnotetext{
${ }^{1} \mathrm{~A}$ similar distinction between metaphysical and phenomenological transparency is also drawn in Gow 2016. The Appearance View is committed to phenomenological transparency, not metaphysical transparency.
} 
such that it is not phenomenally present to other conscious subjects. Indeed, subjective character and for-me-ness are thought to be essential properties of any phenomenally conscious state: whereas qualitative properties make a mental state phenomenally conscious of this or that object, having a subjective character just is what makes a mental state phenomenally conscious at all (Kriegel 2009, 17). The claim of reflexivity theorists is that a conscious mental state has a subjective character that is, has something it is like 'for me' - in virtue of a that state's having a reflexive inner awareness of itself.

Though we are warned by reflexivity theorists that a conscious state's subjective character or for-me-ness are uniquely difficult or even impossible to introspect (Kriegel 2009, 185, see also Montague 2017), we can draw some further clues about the phenomenal character of reflexive awareness from Kriegel's claim that a subject's ubiquitous inner awareness of its own conscious mental states is often 'peripheral' in nature. Outer awareness is readily acknowledged as having a center/periphery structure: while being focally aware of the laptop screen in front of me, I am still consciously aware of a mug in the periphery of my visual field, as well as the background auditory hum of the refrigerator, the tactile sensation of carpet against my feet, and so on. Kriegel's claim is that any conscious outer awareness of an object is often accompanied by a peripheral inner awareness of that awareness itself. Now, it may be impossible to introspect any given instance of peripheral inner awareness, because as soon as a subject directs attention to that inner awareness, it is placed in the center of one's conscious experience and hence is no longer peripheral. Still, the unintrospectibility of peripheral inner awareness is compatible with its always being phenomenologically manifest in any and every conscious experience, no matter how strange it may seem for there to be aspects of one's conscious experience that, in principle, one can never notice. In fact, Kriegel thinks that UIA doesn't conflict with the transparency intuition, if understood as the claim that every introspectible aspect of an experience is part of the experience's first-order representational content $(2009,182)$. Since peripheral inner awareness isn't introspectible, it doesn't conflict with the claim that all introspectible phenomenal properties of a conscious state are properties of the objects that state represents.

Nonetheless, even if the contribution that peripheral inner awareness makes to the overall phenomenal character of a subject's perceptual experience is unintrospectible in any given moment, we should still be able to discern what that contribution is and how it differs from the 
phenomenal character of either focal or peripheral outer awareness. The problem is that there seems to be no obvious candidate for what this distinct contribution would be, one which could demonstrate to a proponent of the Appearance View that they've been mischaracterizing their own phenomenology as solely presenting appearances of the world rather than appearances of awareness itself. On the Appearance View, you are transparently aware of the visual appearance of a blue sky (if not the blue sky itself); whereas for the reflexivity theorist, you are aware of both the objective appearance of the blue sky as well as the subjective experiencing of that blue sky. But, if we assume that, under the Appearance View, every appearance is a conscious phenomenal appearance, then to be phenomenally aware of the experiencing of the blue sky is just to be aware of the blue sky's phenomenally appearing. That is to say, the Appearance View proponent can accommodate the purported fact that being aware of a blue's sky phenomenally appearing involves being aware of the blue sky through a first-personal mode of phenomenal presentation, which is thought by the reflexivity theorist to constitute a conscious experience's intrinsic for-me-ness. The Appearance View can grant that being phenomenally aware of the world inevitably involves being aware from within a certain spatiotemporal perspective, which for a conscious subject is an inherently first-personal point of view. That being so, the qualitative features of the blue sky's appearance would include whatever sorts of perspectival properties that would be entailed by the blue sky's appearing from that first-personal point of view. All the while, the subject would be aware of the world's perspectival appearance-properties alone, in which case its inner awareness of experiencing the world's appearance-properties would be no different than its outer awareness of those appearanceproperties, again assuming that such appearance-properties are already and only instantiated in phenomenally conscious states occurring within a first-personal perspective. In other words, the Appearance View would entail that every aspect of one's inner awareness of experiencing the blue sky's appearance would be identical to one's awareness of some aspect of the blue sky's appearance - being aware of experiencing the appearance would hence be no different from being aware of the appearance being experienced. If the Appearance View is true, then, it would be further implausible to maintain that at the same time one is focally aware of the blue sky's subjectively experienced appearanceproperties, one is also peripherally aware of those same appearanceproperties. 
Kriegel does hint at a more robust way of describing what a subject's inner awareness is like beyond its being merely peripheral. He suggests that, in addition to a subject's inner awareness of an experience of some object, the subject can also have an inner awareness of itself. That is to say, a conscious mental state can be pre-reflectively self-conscious not just in being aware of itself, but also through being aware of the self to whom the state belongs. Guillot (2016) helpfully characterizes this more substantive type of subjective character as involving a phenomenal quality of 'me-ness' whereby the subject pre-reflectively appears within a conscious state, as against a conscious state's more rudimentary quality of 'for-me-ness' whereby the state pre-reflectively appears to a subject. If conscious states did in fact have an intrinsic character of meness, then the Appearance View would be false - the subject's appearance within a conscious state would mean that not all of the state's phenomenal qualities supervene on how the world appears. Yet, this specifically 'egological' rendering of pre-reflective self-consciousness is controversial among reflexivity theorists, some of whom would think that pre-reflective self-consciousness is fundamentally non-egological and thus does not intrinsically contain any quality of me-ness. These theorists claim that reflexive awareness is of conscious states alone, rather than of those states as belonging to an 'I' (Kapitan 1999). Kriegel also allows that not every instance of ubiquitous inner awareness will involve the peripheral awareness of oneself, as over and above the peripheral awareness of one's mental states. For example, infants and nonhuman animals may lack the metacognitive capacities to represent themselves as subjects or as the sorts of things which can possess experiences, even though they still have a more basic inner awareness of their mental states in virtue of which those states have a phenomenally conscious subjective character (Kriegel 2009, 177-8).

However, if pre-reflective self-consciousness is fundamentally non-egological, and amounts just to a conscious state's having a phenomenal character of for-me-ness, then we still cannot point to anything in the state's phenomenal character that outstrips the character of the world as it phenomenally appears. Put simply, if the notions of for-me-ness or subjective character postulated by reflexivity theorists only capture the fact that a certain mental state is phenomenally conscious, then there is nothing within those notions which would entail that a mental state is not just phenomenally conscious of how the world appears. We aren't any closer to discerning what would be the intrinsic and proprietary phenomenal character of a state's reflexive awareness of itself, as distinct 
from its awareness of an object's qualitative appearance-properties. As a result, phenomenological reflection on the subjective character of a conscious mental state does not yet provide convincing evidence to support UIA (see also McClelland 2015).

\section{A Dignāga-inspired defense of UIA}

The 5th century Buddhist philosopher Dignāga comes closer to characterizing the phenomenology of a conscious state's subjective character in a way that doesn't reduce to the phenomenal character of objective appearances. As we will see, the answer he gives for what counts as the subjective character of conscious mental states is particularly suggestive in comparison with Watzl's own account. Dignāga posits that awareness has two types of phenomenal forms, structures, or appearances (rūpa, äkāra, äbhāsa): an appearance of an intentional object, and an appearance of the conscious state itself. Dignāga agrees with Zahavi and Kriegel $(2016,41)$ that the first-order awareness of an object is phenomenologically different than the second-order awareness of the firstorder awareness: If experience involved only the transparent presentation of an intentional object, then there would be no difference between perceiving an object and subsequently introspecting that perception, since nothing else would appear in the subsequent awareness other than just the appearance of the transparently perceived object (see also Kellner 2010, 206-216). Since the first-order perception and the subsequent second-order awareness are evidently distinct, the first-order perception must also have contained some other appearance apart from the appearance of its object - namely, an appearance of itself (svābhāsa). That being so, when the second-order awareness (A2) represents the first-order perception (A1) as its own intentional object (A2-O), it will represent the first-order perception's object-appearance (A1-O) and also its self-appearance $(\mathrm{A} 1-\mathrm{S})-$ i.e. $\mathrm{A} 2-\mathrm{O}=\mathrm{A} 1-\mathrm{O} \& 1-\mathrm{S}-$ in addition to containing a subjective appearance of itself (A2-S). If there were no $A 1-$ $\mathrm{S}$ and $\mathrm{A} 2-\mathrm{S}$, then $\mathrm{A} 2-\mathrm{O}=\mathrm{A} 1-\mathrm{O}$, which would implausibly give $\mathrm{A} 2$ the same phenomenal appearance as $A 1$. Therefore, the existence of a subjective appearance in each awareness-state should be admitted in order to prevent any subsequent awareness of a prior state from simply replicating its phenomenal appearance through taking the prior state as its intentional object (PSV 1.11ab; Steinkellner 2005, 4.20-25).

Now, we won't dwell here on the possible shortcomings of Dignāga's argument; more relevant for our purposes is how he elsewhere 
characterizes the subjective self-appearance belonging to every state of object-directed awareness. When the subsequent awareness takes a first-order perceptual awareness as its object, it reveals that first-order awareness as having contained both an appearance of an object and the affective manner in which that object-appearance was subjectively presented, e.g. as being desirable or undesirable. As we will explain shortly, these two objective and subjective appearances must both be reflexively known at the time of the perceptual state's occurrence (PSV 1.9b; Steinkellner 2005, 4.6-8). Following Dignāga, Dharmakīrti offers some reasons for thinking that the affective states of desirability/undesirability, and hedonic states of pleasure/pain/neutrality associated with every awareness cannot be (at least ontologically) identified with or reduced to the appearance of an object. For instance, the same apparent object can be experienced as desirable by some subjects and undesirable by others; since the same object can't have contradictory properties, the felt qualities of desirability or undesirability cannot be qualities of the object itself. Instead, these qualities are experienced as being of the nature of awareness itself. $^{2}$ Nor are these affective qualities present only in the content of a post-perceptual conceptual judgment and retroactively superimposed onto a perceptual object-appearance, since the divergence in felt desirability or undesirability between different subjects can occur at the level of their respective non-conceptual perceptual states (PV 3.344; Tosaki 1985, 29). Dharmakirti further concludes that the hedonic states of pleasure and pain are types of awareness themselves, being that they are essentially subjective modes through which one is aware of an apparent object. Like any awareness of an object, pleasure and pain arise from that object and also have the appearance of that object reflected within them, such that an object-appearance is made known at the same time that the pleasure reflexively makes its own subjective nature known (PV 3.266-267; Tosaki 1979, 361-362). That said, even with the reflexive awareness of pleasure and pain being tinged with the appearance of some object, Dharmakirti insists that there is a basic phenomenal difference between any awareness of an object -

\footnotetext{
${ }^{2}$ PV 3.340-341; Tosaki 1985, 25-27: 'yadi istākāra ātmā 'syā anyathā vā 'nubhūyate / isto 'nisto 'pi vā tena bhavaty arthah praveditah // vidyamāne 'pi bāhye 'rthe yathānubhavam eva sah / niścitātmà svarūpeṇa nānekätmatvadoșatah //' 'Depending on whether the nature of awareness is experienced as having the appearance of being desirable or the contrary, an object is made known as being desirable or undesirable by means of that awareness's appearance. Even though an external object is present, that object's nature is ascertained only according to the experience of it, and not in itself, on account of the fault that the object would have multiple natures [i.e., if the object's being ascertained as desirable or undesirable by different subjects corresponded to how the object exists in itself]'.
} 
states of pain and pleasure included - and an awareness's awareness of itself: An object appears in awareness to be external to, but apprehensible by, that awareness, while the awareness itself always appears to be internal, non-objective, and that which does the apprehending of the object. $^{3}$

However, while the subjective appearance of desirability or pleasure can be conceptually distinguished from the objective appearance of some desirable or pleasurable intentional object, it is still not totally obvious that affective or hedonic states can't be accommodated within the Appearance View. In other words, it isn't clear whether phenomenological reflection alone can establish that phenomenal appearance of pain and pleasure do not supervene on how the world appears. Classical Nyāya philosophers disputed the Buddhist claim that hedonic states exist solely within the subjective character of awareness, taking instead a direct realist view of pleasure and pain as objective contents of perceptual awareness (see Matilal 1986, 292-308). Modern representationalists (e.g. Dretske 1995; Byrne 2001; Tye 2005) also characterize the phenomenology of hedonic sensations as involving the representation of objective states of affairs, namely physical events in one's body. So, for example, through representing some bodily damage in my shoulder, I come to feel my shoulder as phenomenally appearing to be in pain - the pain appears to be a quality belonging to my shoulder, rather as being a quality merely of my subjective experience. Finally, even though Dignāga and Dharmakirti claim that pleasure and pain do not themselves appear as objects of awareness, they would still acknowledge that objects of awareness do appear as pleasurable or painful. ${ }^{4}$

Though, perhaps these Buddhists were on to something. The Dignāgainspired account of subjective character as intrinsically hedonic and affective can stand a better chance against the Appearance View than its contemporary reflexivist alternatives when we keep in mind that the phenomenal experience of pain/pleasure or desirability/undesirability

\footnotetext{
${ }^{3}$ PV 3.427; Tosaki 1985, 108: 'bahirmukham ca tajjñānam bhāty arthapratibhāsavat / buddheś ca grāhikā buddhir nityam antarmukhätmani //' 'Possessing the appearance of an object, the awareness of that object appears as facing outward. And, the awareness which apprehends awareness always faces inward toward itself'.

${ }^{4}$ As Dignāga's 8th century commentator Jinendrabuddhi writes (PST ad PSV 1.9d; Steinkellner, Krasser, and Lasic. 2005 72.14-16): 'That is to say, reflexive awareness manifests in whichever way that an object's phenomenal form enters into awareness as having a nature which is pleasant, unpleasant, etc. And, it is in whichever way reflexive self-consciousness appears that an object is ascertained as having a nature which is pleasant, unpleasant, and so on'. 'tathā hi yathā yathā arthākāro jñāne sanniviśate śubhāśubhādirūpeṇa, tathā tathā svasamvittị prathate. yathā yathā ca sā khyāti, tathā tathā artho niścìyate śubhāśubhädirūpādiḥ'.
} 
often, or even necessarily, has a motivational component. Part of what it is like to experience affective or hedonic states is to experience these states as having motivational force: e.g. an object's appearing as desirable prompts the subject to act and attain it; the appearance of pain in my shoulder calls on me to alleviate and protect against it. However one wishes to explain the source and character of affective/hedonic experience's motivational impact on a subject (e.g. as being grounded on a mental state's representational content or functional role; see Cutter 2017; Aydede and Fulkerson 2019), it seems plausible to construe the phenomenal character of such experience as not supervening solely on how the world appears to a subject. One reason why the felt motivational impact of affective/hedonic states can't be fully assimilated into the phenomenal character of the apparent world is that these sorts of states have a world-to-mind direction of fit, meaning that they are telling the subject what to do, rather than merely telling the subject what the world is like (Watzl 2017, 124). ${ }^{5}$ Specifically, these states call on the subject to carry out some activity that extends beyond the experience of the state itself. This activity might be passively instigated by the experienced state, or agentively initiated in response to it. Either way, by acknowledging that the overall phenomenal experience of affective/ hedonic states contains a motivational aspect which is felt to implicate the subject in that experience, we come closer to identifying what it would be like for states to have a subjective character that does not just replicate what it is like to phenomenally represent external or bodily events.

But, the Dignāga-inspired account still faces a couple difficulties in establishing the truth of UIA and overturning the Appearance View. Firstly, one would already have to be committed to the Buddhist view that all states of awareness are accompanied by an affective/hedonic valence if one were to take that valence as being the basis for our ubiquitous inner awareness of any awareness-state's subjective character. Even if most awareness-states do in fact have such valence, it's not clear that every awareness-state does, in which case there still would be some

\footnotetext{
${ }^{5}$ It may be noted in this regard that Kriegel $(2009,103)$ views inner awareness as having a mind-to-world direction of fit, which is perhaps part of the reason why his version of UIA cannot adequately counter the Appearance View. If, as Kriegel claims, 'the inner awareness of a visual experience is veridical if the world is the way the awareness represents it to be. In this respect, it is not different from outer awareness' $(2005,40)$, then it is difficult to see how at least veridical inner awareness will have any phenomenal character distinct from how the world phenomenally appears. Indeed, this difficulty should apply to all inner awareness, not just veridical instances, given that inner awareness is what constitutes the phenomenal character of any representation's qualitative appearance-properties.
} 
select group of states whose phenomenal character is exhausted just by how the world appears. In fact, many Buddhists consider one type of hedonic valence to have a neutral character that is neither pleasurable nor painful - according to them, a neutral feeling is distinct from pleasure and pain in that, when it arises, there is no desire for it to either remain or go away (e.g. see TB 3cd; Buescher 2007, 56.22-24). Without generating any motivating desires or having any motivational valence themselves, awareness-states which are hedonically neutral would not seem to be action-prompting in the way that pleasurable and painful states are. Accordingly, these states would not seem to contain the sort of subject-implicating motivational force that would otherwise imbue them with a substantive subjective character. If there are indeed conscious mental states with a neutral valence (see Gasper, Danube, and Hu 2021), then inner awareness as construed on the Dignāga-inspired account would not be properly ubiquitous.

Secondly, there is still room to argue that the felt motivational impact of affective/hedonic states is compatible with those states being phenomenally transparent. For example, some have argued that the negative hedonic valence of pain experience lies in the representation of some bodily damage as being bad for the subject (Cutter and Tye 2011; Bain 2017). On this view, the affective character of pain experience is fully compatible with its phenomenal transparency: the motivational force of the experience, which is supposed to both cause and justify a certain response on the subject's part, would still be felt as residing in how the experienced object appears (namely, as being bad). This isn't to say that such a representationalist view is actually correct; the point here is just that phenomenological reflection cannot on its own establish affective/hedonic experience as a counter-example to the Appearance View, and as evidence for UIA.

\section{A Watzl-inspired account of UIA}

\subsection{Attentional structuring and phenomenal priority}

Having seen the difficulties faced by some contemporary and classical reflexivity theorists in articulating the distinctly subjective phenomenal character of ubiquitous inner awareness, we finally come to Watzl's own proposal that we are reflexively aware of the activity of attentional structuring. To briefly summarize his account: Attention for Watzl is the subject-level activity of partitioning occurrent, subject-level states into a 
'priority structure' whereby certain states which are placed at the center of the structure become more psychologically prominent than others. If an attentionally prioritized state is unconscious, then psychological prominence might consist in more information-processing resources being directed to it. When a prioritized mental state is conscious, then this state also becomes phenomenologically prominent in the sense of occupying the foreground or focus of experience. A priority structure comprised of several conscious states is said by Watzl to be phenomenologically manifest as a 'centrality structure' in which states come to be placed in relative positions of phenomenal centrality or peripherality according to the degree to which they occupy the subject's attention. Crucially, the centrality/peripherality relations that conscious mental states bear to each other have their own phenomenal character. For example, not only is there something it is like for an auditory awareness to be the focus of attention, but there is something it is like for a visual awareness to be peripherally attended relative to the focal auditory awareness, where what that is like is not reducible to the phenomenal characters of either attended state individually. Watzl therefore points to these priority relations as making an essential contribution to the overall phenomenal character of a subject's experience which outstrips what is contributed by the appearance-properties of the attended states, even when the latter includes the contributions that attention itself may make to those appearance-properties (e.g. focusing attention on a visual object may increase its apparent size or color saturation). In other words, the phenomenal structure that attention bestows to experience stands as a counter-example to the truth of the Appearance View, in that the phenomenal character of this structure cannot be assimilated into the phenomenal character of the apparent world.

More to the point, the phenomenal centrality structure that attention carves out of conscious experience has an essentially subjective phenomenal character, because that structure is essentially constituted by a subject's mental activity. Attention as Watzl understands it is the dynamic, temporally extended process of creating, maintaining, and reordering priority structures $(2017,53)$. The activity of priority structuring also counts as an activity carried out by a subject, rather than a mere sub-subject physiological process like digestion, because the manner in which attention creates and changes priority structures across time is guided by subject-level mental states. Attentional activity can be either agentive or passive depending on what kind of states are guiding it: Attention is active when it is guided by a hierarchical network of goals, action 
plans, and intentions which Watzl calls the subject's 'executive control system'. Attention is passive when it is guided by the psychological salience of mental states which are not under the subject's executive control. A mental state is psychologically salient to a subject by containing an imperatival content which commands the subject to put that state at the top of a priority structure. At the level of conscious experience, this imperatival content is phenomenally manifest in the way that perceptual, cognitive, and affective states pull and draw one's attention with varying degrees of intensity and to varying degrees of success. When an imperatival command is satisfied, then that state will capture attention and occupy the center of experience, until another state becomes more phenomenally salient and succeeds in either joining the central state or displacing it. The subject can also agentively resist the commands of a phenomenally salient state, preventing it from shaping the centrality structure of experience in the next moment.

\subsection{Active and passive attention awareness}

With the basics of Watzl's account of attentional structuring in view, we can now extend his account to explain how a subject would have a ubiquitous inner awareness of its own conscious states through being reflexively aware of its own attentional activity. Watzl argues that a subject has an inner awareness of its own attentional structuring at least in the case of active attention, where the agent's executive control system guides the process of placing and maintaining certain states at a central position in consciousness. He compares the phenomenology of actively guiding one's attention to the phenomenology of actively moving one's limbs, in that performing these activities makes one additionally aware of both the activity itself as well as the subject that is performing the activity. In the case of movement, there is a clear difference in experiencing oneself as the agent of movement versus experiencing an involuntary movement like a reflex or observing someone else move their limbs. What's missing in the latter examples is the feeling that the positions of one's limbs are moving in response to one's own intentions and volitions. A phenomenal sense of bodily agency hence entails the awareness of own's own subjective intentions and volitions, the relative positions of one's limbs, and the fact that the changes in limb position are linked to those subjective states. Likewise in the case of actively directing attention to some mental state, there is a phenomenal sense of attentional agency through which one is aware of the relative position of mental states 
within a centrality structure, as well as how changes in that position are guided by one's goals, plans, and intentions. Thus, over an above a subject's outer awareness of some object through a mental state, the activity of agentive attentional structuring entails an inner awareness of the phenomenal priority structure in which that mental state is located, as well as an inner awareness of the subject itself as being the source of changes in that structure over time (Watzl 2017, 225-234).

For the inner awareness of attentional activity to be ubiquitous, however, it should also be present when that activity is merely passive and not agentively guided. Watzl himself only argues that subjects have a meta-awareness of their active attention, and so does not endorse the claim that subjects also have a meta-awareness of their passive attentional structuring. Nonetheless, as he also acknowledges (Watzl 2017, 226n6, 280n42), an imperatival theory of psychological salience leaves open the possibility that, even during passively guided attention, subjects can be aware of the phenomenal structuring of their conscious experience. On a Watzl-inspired account, then, the awareness of passive attentional activity would be grounded in the awareness of phenomenally salient imperatival content, as this content is what bestows conscious mental states with a subject-implicating phenomenal character which can't be reduced to those states' appearance properties. So, while the imperatival content unique to pain experience could be plausibly represented as objectively issuing from a represented body part (e.g. <Protect your shoulder!>), the motivational force of a phenomenally salient mental state is felt to issue from the mental state itself (e.g. $<$ put $\mathrm{M}$ at the top of a priority structure!>). And, because salient states bear phenomenal priority relations to other states, becoming aware of one salient state will make a subject aware of other states. Watzl posits that conscious states of a specific sensory modality are located within a 'salience map' for that modality (e.g. visual states are located within a visual salience map). A phenomenal salience map prioritizes the imperatival commands of certain states over other states in the map so as to promote their being subsequently placed at the center of the subject's actual centrality structure. Consequently, because one state's salience is felt in relation to the salience of other states within a salience map, the felt imperatival force of a conscious mental state would also make the subject phenomenally aware of a holistic salience structure.

Furthermore, through making one aware of the mental states that are guiding one's attention, along with the phenomenal priority relations that obtain between them, the imperatival contents guiding passive 
attentional activity would also make the subject aware of the distinctly subjective character of this activity. While active attention makes one aware of being the subject qua agent of attentional structuring, passive attention would make one aware of being passively subject to the activity of attentional structuring and the changes it brings about in one's conscious experience. Watzl $(2017,222-224)$ argues that the temporal dynamics of passive attentional activity are partly responsible for the 'flowing' character of consciousness: There is something it is like for the subject to experience the process of attention being pulled by the imperatival force of a salient perceptual state, that state's moving to the center of its consciousness in the next moment, and finally its receding back into the periphery as another state takes its place at the center. Importantly, these stages of attentional activity are not felt as being disconnected, merely successive events, because as Watzl explains, 'The guiding character of phenomenally salient experiences implies a felt propensity or disposition: if a subject feels her attention being drawn to the sound of the fire alarm she is disposed to attend to that sound (unless something interferes-such as an exercise of executive control)' $(2017,223)$. This phenomenal disposition of a subject's attention to passively shift in a certain way is what relates the initial and subsequent stages of attentional activity so that a subject feels its attention to be guided from one stage to the next. A shift in attention is not felt to come out of nowhere - rather, attention passively shifts because a salient state disposed it to do so, such that the resulting change in the subject's centrality structure is felt to realize that disposition. If the stages of passive attentional activity are indeed felt by a subject to be related across time in the way that Watzl suggests, then we would be able to fill out our explanation of how attentional activity grounds a reflexive and ubiquitous inner awareness of experience's subjective character: Through making the subject phenomenally aware of the process of transitioning from imperatival salience structures to centrality structures, passive attention would make the subject aware of distinctly subjective changes in its experience that are not merely changes in its apparent environment, even if the perception of external changes may be primarily responsible for those subjective changes. Although the flow of its experience is being structured passively by phenomenally salient states, the subjectimplicating character of those states' imperatival contents should make the subject feel that it is also being drawn along in that flow. 


\subsection{Attention-based subjectivity as essential to consciousness}

If I am correct in extending Watzl's account of attention awareness to include a subject's awareness of its own passive attentional activity, then this extended account can be further used to explain how a substantive phenomenal sense of subjectivity is found throughout all conscious experience. Now, Watzl argues that attention is necessary for consciousness, in the sense that a mental state is phenomenally conscious only if it is part of a subject's priority structure (2017, 251-257). But, he goes beyond this necessity claim to hold that attentional priority structuring is essential to consciousness, in that what it is for a state to be phenomenally conscious is for it to be part of a subject's centrality structure (2017, 259). Specifically, attention is responsible for three phenomenal aspects which are essential structural features of consciousness: unity, perspectivity, and subjectivity $(2017,265 \mathrm{ff})$. Our focus is on subjectivity, so I will only briefly summarize the other features. Unity consists in the phenomenal sense that the conscious mental states I experience at any one time all seem to be parts of the same overall experience. According to Watzl, this sense of experiential unity is explained by the holistic centrality structure that attention bestows on experience: a subject's conscious states at any one time are all experienced as being bound together, insofar as what it is like for a subject to experience any single state is partly determined by that state's phenomenal priority relations to all the other states it is experiencing at that time $(2017,268)$. As for perspectivity $(2017,273-$ $275)$, it consists in the fact that conscious experience is always an experience from some distinct point of view and not from another point of view. I experience the world from a distinct point of view to the extent that the centrality structure of my experience cannot be integrated with that of another subject's experience, given that my mental states don't stand in phenomenal priority relations with the states of another subject. The phenomenally perspectival character of a subject's experience cannot be grounded upon its appearance properties, even if the appearance of any given object always involves perspectival aspects (e.g. a coin's appearing to have an elliptical shape from a certain point of view).

Coming now to subjectivity, Watzl draws a useful distinction: Whereas the perspectivity of consciousness amounts to the fact that the subject consciously experiences the world from a point of view, the subjectivity of consciousness consists in the subject's having a point of view on its own conscious experience. The intimate acquaintance of a subject with its own experience - i.e. the first-personal way in which a subject's 
conscious states are manifest to it, as contrasted with the way that nonconscious neural events or the states of other subjects are not manifest is what Kriegel and Zahavi intend to capture with the notions of for-meness and subjective character. Watzl fleshes out these notions by taking subjectivity to be that feature of experience which makes it rational for the subject to ascribe the experience to itself, assuming it possesses the requisite introspective and conceptual capabilities to do so (2017, 278). Even a conceptually capable subject may sometimes or often fail to introspectively access its own conscious states, as in cases of inattentional blindness where it may not notice what it is experiencing (if it indeed experienced the unnoticed state to begin with). Nonetheless, every conscious experience has a phenomenal subjective character which puts the subject in a privileged epistemic position relative to that experience, a position that a subject lacks with respect to the experiences which belong to other conscious subjects.

Watzl argues that a subject has a special acquaintance with its own experience through being aware of its own attentional agency (2017, 276). As we've mentioned, Watzl explicitly holds the view that a subject becomes aware of its own attentional activity through actively guiding it: through voluntarily placing some mental state at the center of its experience, a subject incidentally feels that it is what is doing something to change its experience. To illustrate how the agentive awareness of attentional activity accounts for a subject's privileged epistemic position toward its own conscious experience, Watzl describes several important epistemic features of agentive awareness in general, i.e. of the awareness that a subject has of itself through being the agent of any sort of activity (2017, 230-232). First, agentive awareness provides a pre-cognitive epistemic base for a subject's introspective beliefs about its own activity. That is, a subject can have agentive awareness of its own actions without having to believe or judge that it is acting, and it is this awareness which makes it rational for the subject to believe or judge that it is acting (assuming it has the requisite conceptual capacities to form such beliefs or judgments, and is basing the belief/judgment on its agentive awareness). Additionally, when a subject is agentively aware of moving its finger, say, this awareness is what makes the subject's first-personal judgment that 'I am moving a finger' immune to error due to misidentification with respect to the first-person pronoun. If I am basing this judgment on the awareness I have of actively moving a finger, then I can't judge that someone is moving a finger without also judging that I am moving it $(2017,231)$. 
Given how agentive awareness is generally supposed to place a subject in a privileged epistemic position with respect to its own activity, it is clear why Watzl would cite the agentive awareness of attention as explaining subjectivity as such, which he again understands as the privileged epistemic position that a subject has with respect to its own conscious experience. He summarizes:

Just as actively moving your finger forward makes it rational to believe that you yourself are moving your finger, so actively looking at something (or actively shifting your attention) makes it rational that you yourself are structuring your mind. According to the attentional essence claim this structuring just is your conscious experience. And so agential awareness of attending explains why, by having a conscious experience, it is rational for a subject to believe that she is having a conscious experience. $(2017,279)$

In other words, if the attentional activity of regulating centrality structures is essentially constitutive of what it is (and what it is like) to have a subjective point of view, then the agentive awareness of one's attentional activity would give the subject an inner awareness of its own subjective point of view as such, along with the conscious states experienced therein. As a result, this inner awareness explains the subjective character of consciousness to the extent that it grants the subject with a privileged epistemic position from which to gain introspective knowledge of its own experience.

However, it isn't clear that Watzl can offer a fully adequate explanation of why consciousness has an essentially subjective character only on the basis of agentive attention awareness. The problem is simply this: Subjectivity for Watzl is an essential structural feature of any conscious experience; but, subjects do not always have agentive awareness of their attentional activity - attention can be passively guided instead. So, if an essential feature of consciousness is something that any conscious state should have, then a subject's agentive attention awareness cannot be fully responsible for the essential subjectivity of conscious experience. Watzl can't consistently maintain that subjectivity consists in a special acquaintance with one's conscious experience and is also an essential feature of any conscious experience as such, if he is further committed to the claim that one has this special acquaintance only when one is actively guiding attentional structuring. By contrast, Kriegel and Zahavi can theoretically explain the essential subjectivity of consciousness in terms of the pre-reflective for-me-ness that is an intrinsic aspect of every conscious state, even for those states which belong to pathological subjects like schizophrenics whose general sense of mental agency is so 
disturbed that they don't experience certain thoughts as being under their control (see Henriksen, Parnas, and Zahavi 2019).

Fortunately, Watzl's account of attention has the resources to meet this simple objection against its explanation of subjectivity, once it acknowledges that passively guided attention also acquaints the subject with how its own conscious point of view is being structured. As discussed above, passive attentional activity is guided by the imperatival contents of phenomenally salient states. These contents command the subject to place their respective bearers at the center of the subject's experience. Phenomenally salient states are also holistically related to other states through being located in salience maps that determine which state's imperatival commands should be prioritized for the subject. Once a certain state has captured attention such that its imperatival command is satisfied, the subject's current centrality structure is rearranged with that state at its center. This guided transition in the stages of attentional activity - from attention's being captured by a state's phenomenally salient imperative to then restructuring consciousness in line with that imperative - brings with it a felt transition in the subject's experience, which thereby contributes to the subject's sense that its consciousness is a continuously flowing stream $(2017,213)$. Crucially, these stages of passive attentional activity are felt to be related across time, and the felt transition of experience across these related stages cannot be fully explained by changes in the experience's appearance properties. So, if Watzl is right that 'in phenomenal salience we feel the activity of attending being guided from one moment to the next' $(2017,223)$, then this feeling of passively guided attention should similarly acquaint the subject with its own conscious point of view, given that attentional structuring in even its passive mode is essentially constitutive of what it is like to experience mental states from within a conscious point of view.

A subject should therefore have an inner awareness of its passive attentional activity which parallels the sort of inner awareness entailed by its agentive attention awareness. Recall that actively guided attentional structuring is supposed to give a subject an inner awareness of the mental state being attended, the holistic centrality structure in which that state is located, and the subject as being the source of changes in that centrality structure over time. Likewise, a subject's awareness of its passively guided attentional activity should entail an inner awareness of phenomenally salient states and their holistic salience structure, the new centrality structure that results from a salient state's capturing of attention, and ultimately the conscious point of view itself that is 
being restructured as attention passively flows from one stage of activity to the next. Just like agentive attention awareness, this inner awareness of passive attentional activity should similarly provide the subject with an implicit, incidental perspective on its own conscious experience. To feel one's attention passively shifting and flowing from moment to moment is to feel the structuring activity that Watzl thinks is essential to conscious experience. This feeling of experience being dynamically restructured by passive shifts in attention must have a distinctly subjective phenomenal character, since it cannot be fully determined by changes in an experience's appearance properties. That being so, we would thus have in both agentive and passive attention awareness the sort of special acquaintance with conscious experience itself which Watzl takes to define subjectivity as such: Agentive attention awareness makes it rational to believe that you are structuring your experience, and passive attention awareness should similarly make it rational to believe that your experience is being structured. It may be that passive attention awareness is a further step removed from a subject's introspective access, since one would first have to actively attend to the passive restructuring of experience by phenomenally salient states before one could then form beliefs about the experience of those states. Nonetheless, both agentive and passive attention awareness should serve as the privileged epistemic base for introspective knowledge, insofar as both forms of awareness have a phenomenal character which acquaints the subject with the attentional activity that constitutes what it is like to have a conscious point of view in the first place.

\subsection{The advantages of a Watzl-inspired account of reflexive inner awareness}

We can now appreciate how, once it incorporates passive attention awareness into its explanation of subjectivity, Watzl's account of attentional activity stands to improve upon the other the reflexivity theories we've surveyed in countering the Appearance View and establishing UIA. We saw earlier how contemporary theorists like Kriegel and Zahavi fall short of substantively describing the subjective character of experience in such a way that avoids making it phenomenally redundant: The phenomenal character of 'for-me-ness', which intrinsically belongs to any conscious state and supposedly grounds the subject's reflexive inner awareness of that state, may not be experientially distinguishable from the phenomenal character of a state's appearance properties. The 
Dignāga-inspired model of subjective character manages not to be redundant to the extent that it would identify the 'for-me-ness' of experience with the subject-implicating motivational force of the affective and hedonic valences that accompany most every experience. Still, the scope of this model would be limited to experiences with non-neutral affective/ hedonic valences, which prevents it from being a non-redundant account of ubiquitous inner awareness. Also, it isn't obvious that the felt motivational force of an affective/hedonic state cannot be assimilated into how the world appears.

By contrast, the reflexive and ubiquitous inner awareness of passive or active attentional structuring would make a substantive, non-redundant contribution to a subject's overall conscious experience, in that it bestows experience with a phenomenal subjective character which cannot be reduced to the qualitative character of objective appearance properties. Again, this phenomenal sense of subjectivity would resist any reduction under the Appearance View for several reasons. The phenomenal centrality structures that attention generates are holistic, since they are constituted by not only the phenomenal states which are its parts, but also the phenomenal relations that each state in the structure bears to each other. This means that, within the total phenomenal experience of a centrality structure, the phenomenal character of any individual state will be constituted not just by the qualitative aspects of that state's content - e.g. its qualitative appearance properties - but also by its relations to other states. For example, it is constitutive of what it is like to experience the background hum of the refrigerator that the hum is phenomenally peripheral to the visual awareness of the laptop that is phenomenally central, and vice versa. Thus, no matter how transparent each mental state would seem to be in presenting their own objective representational contents, they would still contain an irreducibly subjective phenomenal character as well - not in virtue of intrinsically possessing some atomic quality of 'for-me-ness', but through their phenomenal relations with other subjective states situated within a holistic centrality structure. Indeed, the phenomenal holism of Watzl's account $(2017,203-208)$ insulates it from the fault of redundancy posed to atomistic models of reflexive inner awareness by the Appearance View. It is more plausible to hold that reflexive inner awareness and its proprietary subjective character emerge through the subject's activity of attentionally structuring its mental states into a complex, unified whole.

A Watzl-inspired, attention-based account of reflexive inner awareness also has several advantages over two other construals of pre-reflective 
self-consciousness proposed by McClelland (2015) and Howell (2019). McClelland and Howell also argue that UIA defenders like Zahavi and Kriegel have failed to adequately address skeptics who would invoke the transparency of experience in order to deny that phenomenological reflection reveals a ubiquitous inner awareness of phenomenal for-meness. They too suspect that a conscious state's purely intrinsic subjective character, being unable to phenomenally differentiate itself from the qualitative properties of a state's representational content, cannot suffice for grounding a non-trivial form of self-consciousness which makes a subject aware of itself as having a conscious mental state. Instead, McClelland and Howell both suggest that a subject has a prereflective inner awareness of a first-order mental state which consists in the sense that the first-order state could be reflected upon, i.e. that the state affords introspection and self-ascription. According to McClelland, the experience of at least normal adult humans is ubiquitously characterized by the affordance of introspectibility - just as a perceived football can phenomenally manifest as being kickable, all conscious experience manifests to a subject as being introspectible (McClelland 2015, 2484-2485). As for Howell, he takes pre-reflective self-consciousness to involve a nonconscious, non-occurrent belief that the subject could reflect upon and self-ascribe any of its conscious states. Howell is slightly more circumspect than McClelland on the issue of phenomenology: The subject's standing belief that any of its conscious states can be self-ascribed does not have any phenomenal character of its own, although it may still color the subject's occurrent experience while remaining non-occurrent. He compares the phenomenal influence of this standing belief to that of a prisoner's belief that he can't escape his cell - this belief conditions how the prisoner experiences and interacts with his surroundings even when he is not actually thinking about it (Howell 2019, 181). In the same manner, I am implicitly aware of the possibility that I can reflect on and self-ascribe my experiences, even if I am not reflecting on that fact at any given moment. For both McClelland and Howell, then, there is a form of ubiquitous inner awareness which acquaints a subject with its own conscious states, and which imbues those states with a substantively subject-implicating phenomenal character. Through being pre-reflectively aware of the possibility that one could reflect upon and self-ascribe a given mental state, one is thereby aware of oneself as the subject for whom those introspective activities are a possibility.

McClelland and Howell's alternative construals of inner awareness bear some resemblance to Watzl's original explanation of subjectivity. All three 
reject the idea that the subject's privileged perspective on its conscious experience can be grounded upon on any single state's awareness of itself or its own intrinsic for-me-ness. They instead accept that a subject has a special acquaintance with their states only to the extent that these states can be related to some mental activity that the subject agentively performs. For McClelland and Howell, that activity is introspective reflection, while for Watzl it is actively guided attention. This point of difference belies the way in which their accounts could be synthesized: The pre-reflective possibility of introspection which McClelland and Howell identify as accompanying a conscious state would be explained by Watzl as being brought about through the subject's agentive awareness of actively bringing that state into the center of its experience. Agentive awareness is still pre-reflective since it can occur without the subject noticing that it it actively attending to the state, but this awareness of actively attending to the state is what makes it possible for the subject to gain introspective, self-ascriptive knowledge about that state, since it's through this agentive awareness that the subject is both aware of the state and of itself qua subject of that state. So, it seems that McClelland, Howell, and Watzl are all on common ground in understanding the inner awareness of subjectivity to based upon the felt possibility that a subject's current experience could be introspected.

That being said, the Watzl-inspired account of ubiquitous inner awareness is better positioned to substantively explain the phenomenal character of subjectivity as such. To start, the inner awareness of active and passive atttentional activity would be properly ubiquitous, whereas the inner awareness of a state's introspectibility would not. As Howell and McClelland would acknowledge, the standing belief in or felt affordance of introspectibility can only be a ubiquitous feature of experience for creatures who have the conceptual capacities required for introspective reflection and self-ascription. Consequently, their accounts can't explain the subjectivity that is supposed to be essential to consciousness, since there presumably are creatures who have conscious experiences but don't have the capacity to meta-cognitively access and form judgments about them. Such creatures would not feel their conscious mental states to afford introspection, despite having the sort of special acquaintance with those states which is essential to their being conscious. On the other hand, Watzl's account has the advantage of taking agentive attention awareness to be pre-cognitive and occurring independently of introspective access. A subject incidentally gains an awareness of its own mental activity through agentively directing its attention to the world 
$(2017,229)$, and this awareness doesn't require the subject to possess a sophisticated theory of mind that would enable it to conceive of its mental states as being introspectible, as at least Howell's account would seem to require. Yet, agentive attention awareness is also not ubiquitous, since subjects are not always actively guiding their attention in every moment of conscious experience.

Thus, it is only with the acknowledgement of passive attention awareness that Watzl can fully explain phenomenal subjectivity - i.e. the acquaintance that grants a subject with a privileged epistemic perspective on all of its conscious experience - in terms of a subject's reflexive awareness of its own attentional activity. I've argued that Watzl's account can be plausibly extended to incorporate the reflexive inner awareness that a subject has of its conscious point of view as it is being passively restructured by phenomenally salient states. The awareness of phenomenal salience and its subject-implicating motivational force could also occur independently from introspective access, and would be non-conceptual in the sense that a subject wouldn't need to possess concepts like phenomenal salience or centrality structure in order to experience a salient state's command that the subject place the state at the top of its centrality structure $(2017,127) .{ }^{6}$ In line with how Buddhists like Dignāga understand reflexive awareness, passive attentional activity would grant a subject with a reflexive inner awareness of its own conscious mental states that is non-conceptual and pre-cognitive. But, contra Dignāga, this inner awareness is not adequately explained in terms of the intrinsic awareness that a momentary and atomic mental state has of itself. Rather, a subject's inner awareness of its own mental states is better explained in terms of the awareness a subject has of its mental states as they are being actively or passively arranged by attention into the holistic centrality structure that constitutes the unified perspective through which the subject experiences the world. On the Watzl-

\footnotetext{
${ }^{6}$ Following Heck (2000), there are two possible ways in which the imperatival contents involved in phenomenal salience would count as non-conceptual. Under a 'state view', a state is non-conceptual if a subject bears a concept-independent relation to that state, which is to say that the subject doesn't possess any concepts which would articulate that state's content. Imperatival contents as Watzl understands them would be non-conceptual under the state view, in that a subject can undergo salient states without possessing concepts relevant to articulating the content of those states' attentional commands. However, it's not clear whether these contents as construed by Watzl would also count as non-conceptual under a 'content view', which holds that states are non-conceptual only if their contents have a structure and function which are different in kind from that of conceptual states. It doesn't seem that the imperatival content <put $\mathrm{M}$ on the top of a priority structure! > would be different in kind when experienced by someone who (having read Watzl's book) possesses the concept of a priority structure. In that case, concept possession would be irrelevant to whether the imperatival contents of salient states are essentially non-conceptual in nature.
} 
inspired account, a subject would have a reflexive inner awareness of the temporally extended activity of attention as it flows from one centrality structure to the next, thereby acquainting the subject with its own conscious perspective as it's being constantly sustained or reshaped by this activity. The subjective character of conscious experience which is grounded upon the awareness of attentional activity can still be pre-cognitive and non-introspective. Even infants and non-human animals would be acquainted with their own conscious point of views, insofar as they can pre-reflectively exert mental agency in actively directing their attention, and/or their attention passively flows such that their experience is prereflectively felt to change in a way that can't be assimilated to how the apparent world has changed.

\section{Attention-based subjectivity and minimal phenomenal experience}

Despite whatever advantages it may have over competing reflexivity theories in establishing UIA, the Watzl-inspired account still raises a number of further questions about its independent plausibility. In this section, I'll focus on one such question: Is attention-based subjectivity actually essential to consciousness, as this account following Watzl would suggest? The basic claim again is that a subject has a phenomenal acquaintance with its own conscious experience in virtue of being aware of the way that attention structures experience into center and periphery. Furthermore, in being aware of the activity of attentional structuring, the subject has a pre-cognitive phenomenal sense of being the subject of experience, in that it can feel itself to be the active subject/agent of, or passively subjected to, this structuring activity. One preliminary question now arises: What sort of phenomenology is involved in feeling oneself to be the subject of experience qua subject of attentional structuring? This feeling can't be some sort of sensory phenomenology, since the Watzlinspired account holds that phenomenal centrality structures cannot be reduced to sensory appearance properties. It can't be a form of cognitive phenomenology in the sense of arising from occurrent thoughts, since the phenomenal acquaintance with one's own attentional activity takes place independently of whether one is thinking about that activity. Perhaps Watzl would admit some sui generis, non-sensory and non-cognitive form of attentional phenomenology.

Whichever kind of phenomenology it may involve, I think that the awareness of attentional structuring must at base consist in an awareness 
of experiential change. Given that attention for Watzl amounts to the activity of structuring phenomenal experience into a center and periphery, the changes that attention brings about in this center/periphery structure should correspond with changes in one's phenomenal experience overall. My suggestion is that under a Watzl-inspired account, a subject would be reflexively aware of its attentional activity, as well as the phenomenal subjectivity that this awareness underpins, through tracking the corresponding changes in the phenomenal structure of experience. In the case of actively guided attention, the subject becomes agentively aware of attention when it feels the centrality structure of its experience to change in response to its own intention and effort to change it. A subject would be aware of passively guided attention when it feels its centrality structure to change as a result of the felt imperatival commands of its phenomenally salient states. Additionally, even if the phenomenal structure of experience is not currently changing due to being actively maintained by the subject as it fixes and sustains attention on a specific mental state, this structure may still be felt as being disposed to change as other salient states attempt to pull attention elsewhere. Active maintenance of the same centrality structure involves resisting the felt propensity of that structure to change.

If it is right to posit a constitutive link between the phenomenology of attention awareness and the awareness of attention-driven experiential change, then we can reframe the question about whether there is also a constitutive link between attention-based phenomenal subjectivity and consciousness as such. According to the Watzl-inspired account of UIA, a subject is acquainted with its own conscious point of view through the reflexive awareness of how its conscious point of view is being structured by attention. Now, I have suggested that agentive and passive attention awareness should be tied to an awareness of corresponding changes in the phenomenal structure of experience. If that is so, then we may raise the following questions for the Watzl-inspired account: Could it be possible to have conscious experience in which there is no awareness of any phenomenal change or possibility of change to a centrality structure, and hence no subjective acquaintance with a conscious point of view? Does the Watzl-inspired account predict that when the phenomenal flow of attentional structuring is ceased, the phenomenal sense of subjectivity is also ceased? And finally, if the sense of subjectivity engendered by attentional structuring is essential to consciousness, would the absence of an inner awareness of attentional change entail an absence of consciousness? 
If the answers to these questions are affirmative, then a straightforward way of falsifying the Watzl-inspired account of UIA would be to find cases of conscious experience where there is no attentional structuring, no corresponding sense of experiential change, and thus no attention-based sense of being a subject. Though their existence is controversial, there are potentially two such cases: lucid dreamless sleep (LDS; Thompson 2015; Windt 2015) and non-dual meditative awareness (NDA; Metzinger 2020). As described by Windt, lucid dreamless sleep is a state of phenomenal experience that is devoid of any intentional contents as well as minimal phenomenal selfhood. That is, consciousness is preserved even though one is not conscious of the sorts of intentional objects typically found in dreaming sleep or ordinary waking awareness - e.g. sensory imagery or propositional thought-contents. And, consciousness in LDS lacks any phenomenal sense of spatiotemporal self-location within a bounded first-personal perspective, this sense being integral to the most basic experience of being or having a self. Additionally, Windt posits that LDS involves a bare experience of pure phenomenal nowness or temporal duration in the present moment. This means that, in the absence of distinct intentional contents which could differentiate one present mental state from another, there would be no experience of temporal succession or change (2015, 18-19).

The second case is that of non-dual meditative awareness (NDA). Like lucid dreamless sleep, NDA is postulated by some classical Indian philosophers as an example of conscious experience that is devoid of any intentional objects. For instance, Yogācāra Buddhists like Dharmakīrti claim that the dualistic bifurcation of awareness into the two type of appearances mentioned above - viz., the appearance of a subject or subjective state (grähakäkära) that apprehends an apparent objective content (grähyākära) - is actually a deeply rooted cognitive illusion which distorts the non-dual nature of awareness itself. ${ }^{7}$ The distinction between objective appearance properties and the appearance of an internal subject can be eliminated in non-dual, 'supramundane' states of awareness. Metzinger (2020) suggests that such non-dual states as discussed by various Indo-Tibetan contemplative traditions are paradigmatic cases of

\footnotetext{
${ }^{7}$ PVin 1.39-40ab; Steinkellner 2007, 36.2-4: 'avedyavedakākārā yathā bhrāntair nirīksyate / vibhaktalakșanagrāhyagrāhakākāraviplavā // tathā krtavyavastheyam keśädijñānabhedavat /' 'Like the difference between awareness and illusory hair, etc. [which appears to someone suffering from a disorder such as myodesopsia], this condition of differentiation, which is an internal disorder that takes the appearance of an apprehended object and apprehending subject with their distinct characteristics, is brought about according to the way in which those in error regard an awareness that lacks the appearance of a knower and known'.
} 
minimal phenomenal experience (MPE). He takes non-dual states to lack several of the features that many phenomenologists and philosophers of mind, Watzl included, have thought to be essential to any conscious experience.

In particular, Metzinger's description of MPE is relevant to Watzl's claim that attentional activity is responsible for the essentially perspectival and subjective character of consciousness. Similar to Watzl, Metzinger (2017) argues that the basic sense of being a knowing self arises through the exercise of attentional agency: by effortfully initiating a shift in attention and focusing on a certain object, a subject feels itself to be capable of acquiring knowledge of that object from the vantage point of its own first-personal perspective. Conversely, non-dual states are said to lack this experiential structure of a knowing subject as set against knowable objects: Given the purported absence of any sensorimotor, affective, or cognitive intentional contents in NDA, there would be nothing for one to effortfully direct attention toward; any active exertion of attentional control would lead to the re-emerging of a phenomenal subject-object structure. The absence of attentional agency would hence entail the absence of minimal phenomenal selfhood (Metzinger 2020, 36). NDA therefore poses a problem for Watzl's original claim that agentive attention awareness is responsible for the phenomenal subjectivity that is essential to consciousness. Moreover, non-dual states also challenge the Watzl-inspired claim that passive attention awareness generates a phenomenal sense of being a subject. Again, this passive sense of phenomenal subjectivity would be entailed by the feeling of being subject to the temporal flow of experience which emerges from salience-driven changes to one's centrality structure. According to Metzinger, however, MPE as instantiated in NDA is devoid of any temporal character - there is no experience of change and no experience of oneself as being temporally located, even in a phenomenal 'now' (2020, 10-11). Indeed, Metzinger claims that NDA is devoid of any 'passive personal-level self-as-subject' or bounded first-person perspective $(2020,10)$.

Lucid dreamless sleep and non-dual meditative experience threaten the idea that attention-based subjectivity is essential to consciousness, because they seem to be cases of consciousness in which there is no attention-driven experiential change, and therefore no sense of being either an active or passive subject of attentional activity. Now, could a Watzl-inspired account accommodate these cases and hold that that there is still a reflexive inner awareness of attention-based subjectivity, despite there presumably being nothing in experience to suggest that 
attentional activity is taking place? For the sake of argument, let's initially assume that there is an attentional priority structure present in states of LDS or NDE. Such a structure would be totally flat and evenly distributed, since there wouldn't be any mental states which are more central in experience than any others (see 2017, 98). Let's further allow that this totally flat, evenly spread priority structure is maintained passively without any effortful control by the subject. Would this experience still have a phenomenal centrality structure? For his part, Watzl thinks not: A centrality structure is constructed by the phenomenal centrality relations between conscious qualitative states, but if there are no sensorimotor, affective, or cognitive states with qualitative properties in LDS or NDA, then there would seemingly be no relata to instantiate a centrality relation. Since attentional structuring is essential to consciousness for Watzl, such minimal and phenomenally unstructured experiences should be impossible on his view. But, if minimal phenomenal experiences like LDS and NDA are possible and are as Metzinger describes them, then this possibility would undermine a central tenet of Watzl's theory.

Nevertheless, there may be a way to square minimal phenomenal experiences with the Watzl-inspired account, such that a phenomenal sense of attention-based subjectivity would be found even in LDS and NDE. One response to the previous problem - i.e. how could there be a centrality structure if there are no mental states to structure together can be resolved with the posit that attention in LDS and NDA would be diffusely distributed over the entire experience as a whole. To answer the problem of how a centrality relation could involve only one relatum, i.e. the total conscious experience itself, we can draw on a distinction Watzl makes between strict and weak versions of attentional centrality. Whereas strict centrality entails that one qualitative state $x$ is more phenomenally central than another state $y$, weak centrality allows that $x$ is at least as central as $y$. The relevant point here is that weak centrality is also reflexive - every qualitative state is at least as central in experience as itself $(2017,192)$. So, it is still possible under Watzl's account that MPE has a minimal centrality structure: The total experience could figure in a diffusively distributed and passively maintained centrality structure wherein the experience reflexively bears a weak phenomenal centrality relation to itself. The upshot is that an attention-based inner awareness could still be present in states of minimal phenomenal experience like LDS and NDA, one which acquaints the subject with its own conscious perspective even though, in the absence of objective 
spatiotemporal appearances or egological thought contents, this perspective may feel unbounded and hence not much of a perspective at all.

In fact, Metzinger's model of MPE coheres in several respects with the Watzl-inspired explanation of such experience as involving the passive attentional awareness of a flat, minimal centrality structure of which the subject's total experience is the sole constituent. To briefly explain some details of Metzinger's model, one of the defining features of MPE is its phenomenal quality of 'epistemicity', which he describes as the 'phenomenal experience of knowing' or 'subjective quality of confidence' $(2020,22)$. By subjective confidence, Metzinger means a phenomenally felt certitude that a current experience is knowledge or has epistemic value, or an expectation that there will be states of knowledge occurring within the 'epistemic space' of experience. The wrinkle is that with the absence of attentional agency in MPE, there is no objective content to be known and no internally located subject that is felt to be actively knowing $(2020,26)$. That said, there can be non-agentive feeling of 'knowing without an object' in states of MPE that lack a phenomenal subject-object structure but are nonetheless characterized by a 'globalized and effortless meta-awareness' (2020, 24-25).

This non-agentive 'knowingness' or subjective quality of confidence in MPE is further specified by Metzinger as a phenomenological expression of the brain's representation of its own degree of tonic alertness. Functionally speaking, tonic alertness is a property which determines the brain's capacity for sustained attention in the absence of external cues, and its readiness to respond to eventual stimuli. Additionally, this capacity is what enables the executive control of attention and the related capacity for locating oneself in time and space (2020, 32-33). Phenomenologically speaking, the experience of tonic alertness has the qualitative character of intrinsic and sustained wakefulness. What it is to experience bare wakefulness as such is to experience the existence of basic capacities for knowing 'where you are, at what point in time you exist, and how you are currently positioned in the order to things', as well as the phenomenal confidence that these capacities will soon yield knowledge about one's own spatiotemporal location and the world, thereby leading to the re-activation of mental agency and self-control. Until then, the wakeful knowledge of these latent capacities appears through 'an internal representational format which does not yet involve subject/object structure, time-representation, or spatial embodiment. The ensuing phenomenology can therefore be described as selfless, timeless, and non-spatial, as a model 
of an epistemic space, a space in which knowledge states can occur' (2020, 37n25, 37n26).

By translating these basic features of Metzinger's model into terms that are compatible with the Watzl-inspired account, we can dissolve the central problem that minimal phenomenal experience posed to the thesis that attention-based subjectivity is essential to consciousness. The problem was basically that if MPE is a state of consciousness in which there are no objects to attend to and no felt subject who is doing any attending, then there would be no awareness of the activity of attentional structuring. With nothing to be prioritized within it, MPE would seem to lack any phenomenal centrality structure. If there is no centrality structure, then there can be no awareness of attentional activity in Watzl's view. In response, I've suggested that passive attentional activity as Watzl understands may still be present in states of MPE. It may be evenly distributed over the MPE as a whole, and this single-membered centrality structure may be effortlessly maintained. The non-agentive and globalized meta-awareness of MPE that Metzinger posits could then be instantiated on the Watzl-inspired account by the passive attention awareness of the total MPE. In turn, this attentional meta-awareness would account for another feature of MPE states according to Metzinger, viz., the property of introspective availability. For all except the most skilled meditators, it may be exceedingly difficult to actually achieve and especially sustain introspective access to an occurrent MPE. That said, it can be possible to actively direct introspective attention to an MPE which was otherwise accompanied by a non-egoic and effortless meta-awareness (Metzinger 2020, 25). Being introspectively available is what generates the epistemicity or subjective confidence that epistemically valuable states will arise (Metzinger 2020,34). On the Watzl-inspired account, passive attention awareness can equally serve as the privileged epistemic basis for introspective knowledge about one's experience. Here in the case of MPE, passive attention awareness qua global and non-agentive meta-awareness would serve to make the MPE state available to agentive introspective attention. Still, the basic role that passive attention awareness would play in a rarefied state of MPE is not essentially different from the role it would play in ordinary experience; in both cases, passive attention awareness acquaints the subject with the attentional activity that constitutes what it is like to have a conscious point of view in the first place.

The next problem to tackle is this: If there are no intentional contents and no experience of time or space in MPE, then there would not be any 
states with phenomenally salient imperatival contents, and so there would be nothing to passively propel the flow of experience, which is what I've identified as the source of passive attentional phenomenology. Hence, if there would be no experiential change at all in MPE, then how would there be any experience of attentional activity as a temporally extended process of regulating centrality structures, if nothing in the centrality structure is felt to change? The Watzl-inspired solution would be to acknowledge that a centrality structure does not need to actively change in order for a subject to be aware of it - it's enough that the structure is felt as being disposed to change. In the case of MPE, rather than there being some phenomenally salient part of experience which is responsible for a potential change in a centrality structure, the whole MPE itself may be felt as being disposed to change. Again, MPEs are internal representations of tonic alertness, a functional property which determines the brain's level of sustained attention and readiness to receive stimuli, and further enables the capacity for agentive attentional control. This property is phenomenally expressed as the experience of wakefulness, which Metzinger describes as involving the expectation that veridical perceptions will occur $(2020,37)$. As a result, even a seemingly static MPE may still contain a phenomenal sense that the total experience will change, in the form of either an expectation that external salient states will occur, or the feeling that attention can be engaged and agentively controlled. If the minimal phenomenal experience of an evenly distributed centrality structure still preserves the sense that the structure is disposed to passively shift as well as be actively restructured, then a minimal but substantive sense of subjective character - i.e. the phenomenal appearance of a unified subjective perspective grounded in the reflexive inner awareness of attentional structuring (and the capacity for active structuring) - should also be preserved even in MPE. The attention-based perspectivity, unity, and subjectivity that for Watzl are essential to consciousness would therefore be present in an awareness that otherwise feels aperspectival, devoid of spatiotemporal unity, and egoless.

\section{Acknowledgements}

Versions of this essay were presented at the conference, 'Mind, World, and Attention: Themes from Indian and Buddhist Philosophical Theory' held at New York University, and an Author Meets Critics panel on Sebastian Watzl's Structuring Mind at the APA Eastern. I am grateful to the respective organizers of these events - Jonardon Ganeri, as well as Susanna Siegel and John Morrison - for including me as a 
participant. Finally, I thank an anonymous reviewer whose great care and erudition helped me to improve the presentation of Buddhist views.

\section{Disclosure statement}

No potential conflict of interest was reported by the authors.

\section{Funding}

Research for this paper was undertaken as part of the grant project, 'Classical Indian Theories of Perception and Consciousness: A Contemporary Reconstruction' (\#27620419), funded by the Research Grants Council Early Career Scheme of the Hong Kong Special Administrative Region, China University Grants Committee Early Career Scheme.

\section{ORCID}

Amit Chaturvedi (D) http://orcid.org/0000-0003-1774-9870

\section{References}

Aydede, M., and M. Fulkerson. 2019. "Reasons and Theories of Sensory Affect." In The Philosophy of Pain: Unpleasantness, Emotion, and Deviance, edited by D. Bain, M. Brady, and J. Corns, 27-59. New York: Routledge.

Bain, D. 2017. "Evaluativist Accounts of Pain's Unpleasantness." In The Routledge Handbook of the Philosophy of Pain, edited by J. Corns, 40-50. London: Routledge.

Brown, R., H. Lau, and J. E. LeDoux. 2019. "Understanding the Higher-Order Approach to Consciousness." Trends in Cognitive Sciences 23 (9): 754-768.

Buescher, H. 2007. Sthiramati's Triṃśikāvijñaptibhāṣya. Vienna: Austrian Academy of Sciences.

Byrne, A. 2001. "Intentionalism Defended." Philosophical Review 110 (2): 199-240.

Cutter, B. 2017. "Pain and Representation." In The Routledge Handbook of Philosophy of Pain, edited by J. Corns, 29-39. London: Routledge.

Cutter, B., and M. Tye. 2011. "Tracking Representationalism and the Painfulness of Pain." Philosophical Issues 21 (1): 90-109.

Dretske, F. 1995. Naturalizing the Mind. Cambridge: MIT Press.

Ganeri, J. 2012. The Self: Naturalism, Consciousness, and the First-Person Stance. Oxford: Oxford University Press.

Gasper, K., C. L. Danube, and D. Hu. 2021. Making Room for Neutral Affect: Evidence Indicating That Neutral Affect is Independent of and co-Occurs with Eight Affective States." Motivation and Emotion 45: 103-121.

Gow, L. 2016. "The Limitations of Perceptual Transparency." The Philosophical Quarterly 66 (265): 723-744. 
Guillot, M. 2016. "I Me Mine: On a Confusion Concerning the Subjective Character of Experience." Review of Philosophy and Psychology 1: 1-31.

Heck, R. K. 2000. "Nonconceptual Content and the 'Space of Reasons'." Philosophical Review 109 (4): 483-523. (originally published under the name "Richard G. Heck, Jr"). Henriksen, M. G., J. Parnas, and D. Zahavi. 2019. "Thought Insertion and Disturbed forme-Ness (Minimal Selfhood) in Schizophrenia." Consciousness and Cognition 74: 102770.

Howell, R. J. 2019. "Reflecting on Pre-Reflective Self-Consciousness." ProtoSociology 36: 157-185.

Janzen, G. 2008. The Reflexive Nature of Consciousness. Amsterdam: John Benjamins B.V.

Kapitan, T. 1999. "The Ubiquity of Self-Awareness." Grazer Philosophische Studien 57 (1): 17-43.

Kellner, B. 2010. "Self-Awareness (Svasaṃvedana) in Dignāga's Pramāṇasamuccaya and -Vrtti: A Close Reading." Journal of Indian Philosophy 38 (3): 203-231.

Kriegel, U. 2005. "Naturalizing Subjective Character." Philosophy and Phenomenological Research 71 (1): 23-57.

Kriegel, U. 2009. Subjective Consciousness: A Self-Representational Theory. Oxford: Oxford University Press.

Matilal, B. K. 1986. Perception: An Essay on Classical Indian Theories of Knowledge. Oxford: Oxford University Press.

McClelland, T. 2015. "Affording Introspection: An Alternative Model of Inner Awareness." Philosophical Studies 172 (9): 2469-2492.

Metzinger, T. 2017. "The Problem of Mental Action." In Philosophy and Predictive Processing, edited by T. Metzinger and W. Wiese, Chap. 19, 1-26. Frankfurt am Main: MIND Group.

Metzinger, T. 2020. "Minimal Phenomenal Experience: Meditation, Tonic Alertness, and the Phenomenology of 'Pure' Consciousness." Philosophy and the Mind Sciences 1: $1-44$.

Mohanty, J. N. 1992. Reason and Tradition in Indian Thought. Oxford: Clarendon Press. Montague, M. 2017. "What Kind of Awareness is Awareness of Awareness?" Grazer Philosophische Studien 94: 359-380.

Rosenthal, D. M. 1997. "A Theory of Consciousness." In The Nature of Consciousness, edited by N. Block, O. J. Flanagan, and G. Guzeldere, 729-754. Cambridge: MIT Press.

Steinkellner, E. 2005. Dignāga's Pramānasamuccaya, Chapter 1: A Hypothetical Reconstruction of the Sanskrit Text with the Help of the Two Tibetan Translations on the Basis of the Hitherto Known Sanskrit Fragments and the Linguistic Materials Gained from Jinendrabuddhi's Tikā. http://www.ikga.oeaw.ac.at/Mat/dignaga_PS_1. pdf.

Steinkellner, E. 2007. Dharmakīrti's Pramāṇaviniścaya. Chapters 1 and 2. Beijing, Vienna: China Tibetology Research Center, Austrian Academy of Sciences.

Steinkellner, E., H. Krasser, and H. Lasic. 2005. Jinendrabuddhi's Viśälāmalavatī Pramānasamuccayațīkā, Chapter 1-Part 1: Critical Edition. Beijing, Vienna: China Tibetology Research Center, Austrian Academy of Sciences.

Thompson, E. 2015. Waking, Dreaming, Being: Self and Consciousness in Neuroscience, Meditation, and Philosophy. New York: Columbia University Press. 
Tosaki, H. 1979. Bukkyō Ninshikiron No Kenkyū: Hōshō cho 'Puramāna Vārutika' no Genryōron. Vol. 1. Tokyo: Daitō Shuppansha.

Tosaki, H. 1985. Bukkyō Ninshikiron no Kenkyū: Hōshō cho 'Puramāna Vārutika' no Genryōron. Vol. 2. Tokyo: Daitō Shuppansha.

Tye, M. 2005. "Another Look at Representationalism about Pain." In Pain: New Essays on its Nature and the Methodology of its Study, edited by M. Aydede, 99-120. Cambridge: Bradford Books.

Tye, M. 2014. "Transparency, Qualia Realism and Representationalism." Philosophical Studies 170: 39-57.

Watzl, S. 2017. Structuring Mind: The Nature of Attention and How it Shapes Consciousness. Oxford: Oxford University Press.

Windt, J. M. 2015. "Just in Time-Dreamless Sleep Experience as Pure Subjective Temporality." In Open MIND, edited by T. Metzinger and J. Windt, 1571-1604. Frankfurt am Main: MIND Group.

Zahavi, D. 2004. "Back to Brentano?" Journal of Consciousness Studies 11 (10-11): 66-87.

Zahavi, D., and U. Kriegel. 2016. "For-me-ness: What it is and What it is Not." In Philosophy of Mind and Phenomenology: Conceptual and Empirical Approaches, edited by D. O. Dahlstrom, A. Elpidorou, and W. Hopp, 36-53. New York: Routledge. 